\title{
Community Creation by Residents and Tourists via Takachiho kagura in Japanese Rural Area
}

\author{
Shiro Horiuchi \\ Shibauta Institute of Technology, Saitama, Japan \\ Email: horiuchi.shiro@gmail.com \\ Received February 22 ${ }^{\text {nd }}, 2012$; revised April 2 ${ }^{\text {nd }}, 2012$; accepted May 5 $5^{\text {th }}, 2012$
}

\begin{abstract}
Rural communities are disappearing in Japan due to aging, depopulation, and changes in lifestyles. Recently, outsiders such as immigrants, volunteers, and tourists cooperate with residents to revive and maintain rural communities. This paper uses my fieldwork in the rural areas of Takachiho, where the Japanese traditional dance kagura is well-known, to consider the possibility that residents and tourists cooperatively create shared communities. Actually, an increasing number of tourists visit Takachiho to see kagura. Consequently, some dancers miss "classical” kagura, which involved almost exclusively local residents in intimate interactions. Nonetheless, many dancers welcome the influx of tourists and its stimulation of community festivals. Some tourists are attracted to kagura at community festivals, and some dancers and tourists have tried to forge bridges between their groups to create a shared community. The existence of kagura becomes an important common symbol that connects members of local communities.
\end{abstract}

Keywords: Community Boundary; Local Culture; Outsiders

\section{Introduction}

Throughout history, ideas about communities have attracted continuous attention from sociologists (Tönnies, 1887; MacIver, 1924), who have studied various communities in the forms of local villages or cities, companies or schools, and even Internet groups (Delanty, 2003). In general, communities share the features of a reserve, in which members interact intimately and trust one another. Based on secure social relationships, members govern common property resources or manage social capital following the rules or norms of the community (Coleman, 1988; Ostrom, 1990). To maintain the beneficial functions of the community, members almost always reify their membership in some way and exclude outsiders (Cohen, 1985). Indeed, the idea of a community entails some degree of xenophobia. Only when community membership is fixed, do the members feel obliged and willing to obey the rules of the community despite the costs because they can gain benefits from its exclusivity (Olson, 1965). Because membership is fixed, members communicate with one another frequently. Only when the members know one another can they monitor and punish those who violate the rules of the community (Hechter, 1987). The members reify their membership to secure their relationships; such secure relationships, in turn, lead members to further reify their membership. Members continually construct social boundaries between themselves and outsiders to ensure the identity of the community (Lamont \& Molnar, 2002).

To further concretize images of a community, I will examine the historically rural areas of Japan. Japanese rural areas were historically composed of hamlets or shizen-son (Suzuki, 1968), which had fixed memberships. Residents lived most of their lives in the hamlets, where they were assumed to share the same ancestors. Most residents were farmers and were involved in the collective work of agriculture, exchanging mutual help, which was referred to as yui or moyai. They excluded outsiders from their shared resources. Local cultures were represented by, for example, dances, music, and marches, which often became common symbols by which members demonstrated their membership in the community. At times, residents sincerely welcomed certain outsiders before finally excluding them; these welcome/exclusion customs formed the basis of the local cultures in Japanese rural areas (Orikuchi, 2003).

Since the major industrial developments in Japan in the 1960s, the situation in rural areas has changed dramatically (Hosoya, 1998). Most residents are not fully involved in agriculture. Instead, they may have part-time jobs in agriculture. Collective agricultural jobs are disappearing because of greater mechanization, and local cultures are also disappearing because local residents hardly have time for festivals due to their new jobs. Fewer young residents are interested in local cultures, which appear outmoded to them. Many residents have left their home towns for major cities to pursue jobs, studies, or leisure activities. The few remaining residents can hardly sustain the former rural communities. Indeed, the communities in many rural areas are in danger of collapse.

Some Japanese rural areas now invite outsiders to activate or revive their communities. Outsiders consist of immigrants, volunteers, and tourists. Immigrants and volunteers actually revitalize rural areas by operating new businesses through networks that transcend the boundaries of the settled rural areas (Akitsu, 1998), by taking jobs that residents do not fill due to depopulation or aging (Yamamoto, 2003), and by participating in the local culture as new members (Hoshino, 2009). Immigrants and volunteers can really be regarded as new members of rural communities in the sense that they make friends with some residents and are concerned about the future of the community.

Compared with immigrants and volunteers who interact with 
residents directly, tourists have fewer interactions with residents. As a consequence, misunderstandings are more likely to occur between residents and tourists. Previous studies have actually suggested that tourism had negative consequences on local societies (Smith, 1989); for example, tourists may cause residents to abandon the practices that constitute part of their local culture, steal sacred statues, provide few direct benefits to residents, lead local residents to became engaged in the practices of the local culture for monetary gain, and contribute to negative stereotypes due to limited opportunities for direct contact.

Some tourists, however, contribute to the revitalization of rural communities, and local residents have improved their relationships with one another through communication with tourists (Nash, 1996). To attract tourists, rural residents may revive their traditional festivals as part of managing their rural communities (Moon, 1989). Indeed, residents may consciously construct the community imagined by the tourists after welcoming the latter from outside their borders to earn cash income (Yamashita, 2003). Local cultures, which were originally created as commodities to entertain tourists, have often become the basis of the local identity of the residents (Cohen, 1988). These consequences, however, are only by-products of the impact of tourism on local societies. As long as tourists rarely interact intimately with residents, they cannot be regarded as members of the communities, a role that the immigrants and volunteers adopt legitimately.

It remains unclear whether tourists can work with residents to cooperatively create and maintain a shared community in rural areas as do immigrants and volunteers; that is, the ability of tourists to be members of their target communities is uncertain. To revive rural communities, some portion of the tourists should be sufficiently embedded in their target communities to become members. Projects involving "alternative tourism" (Smith \& Eadington, 1992) are expected to revitalize rural communities, perhaps by enticing some tourists to become members of the communities. It is necessary to accumulate case studies to address these issues because individual situations differ greatly from one another. This paper introduces my fieldwork as one examination of the possibility of community creation via the cooperation of residents and tourists.

\section{Takachiho kagura}

Takachiho is located in Miyazaki prefecture in Japan. Although the central part of Takachiho contains many shops, restaurants, and hotels, most areas of Takachiho consist of paddy or vegetable fields, cattle sheds, and mountains with coniferous trees.

Takachiho is famous as a sacred place in Japanese mythology and as the birthplace of kagura ${ }^{1}$, a traditional dance that

\footnotetext{
${ }^{1}$ The myth tells about the sun spirit, Amaterasu, who had hidden herself in a cave formed by rocks, referred to as Amanoiwato, located in Takachiho. When the sun then disappeared from the earth, many spirits tried to remove the rocks to liberate the sun, but this plan failed because the rocks were too heavy to move. Uzume, a spirit related to the arts and joy, danced in front of the rocks. Because her dance was entertaining, all the spirits gathered to watch it. Amaterasu heard the laughter of the spirits from her position behind the rocks. This piqued her interest, and she opened the rocks slightly Then, the powerful spirit, Tajikarao, inserted his arms into the crack and cleared the rocks. The sun then returned to the earth. Uzume's dance is regarded as the origin of kagura.
}

was transmitted to many areas in Japan. Kotegawa (1976) stated that Takachiho kagura probably originated in the Nara era (710-794). According to Yamaguchi (2000), the present style of Takachiho kagura dates from the Kamakura era (1192-1333). In Takachiho, residents have performed kagura every year, including during World War II (1939-1945). During the 1970s, the number of dancers decreased because of depopulation and aging in the area. During those times, Takachiho kagura was selected as an intangible cultural asset by the Ministry of Education, Culture, Sports, Science, and Technology of Japan, and some residents were officially invited to perform kagura in several European countries. Because of these events, which made Takachiho kagura famous, many residents started to participate in kagura after the 1970s. Despite the continued depopulation and aging of the area, kagura is still practiced in 19 areas in Takachiho in $2010^{2}$.

In Takachiho, the kagura season begins in November and lasts until the February of the following year. It usually starts during the evening of a festival day and involves the continuous performance of 33 dances, including formal dances in which audiences welcome local spirits (the dancers), amusing dances in which dancers interact pleasantly with the audience, storytelling dances in which dancers act out stories from mythology, and climactic dances in which audiences say farewell to the spirits that then return to the mountains. The finale occurs the next morning. Kagura is both a prayer to the spirits by the residents and a festival event in which residents interacted intimately with one another, ensuring comraderie within the community. All dancers are traditionally restricted to males.

Residents traditionally selected private homes as kagurayado, places for performing kagura ${ }^{3}$. Historically, private homes in Takachiho had been large because home owners had worked in agriculture and owned cattle. Tradition is important for understanding Takachiho kagura in that the home owners of kagurayado were proud of being selected and having their homes welcome the spirits. Furthermore, dancers and audiences stayed in the same rooms at the private homes. At midnight, dancers and audiences interacted intimately amid great excitement. At times, quarrels occurred among audience members who had had too much to drink. At the end of kagura, audience members were given sacred ornaments used in this tradition. Audiences were largely restricted to the residents of Takachiho, although a few tourists visited from distant areas. Thus, intimate interaction between dancers and audience members was easy, allowing the residents to reinforce their sense of community.

Today, Takachiho residents can barely fit performances of kagura into private homes. Recently built houses are typically small because the owners do not own cattle or work in agriculture. As a consequence, kagura is often performed in public buildings. In 2009 and 2010, respectively, nine and 10 of the 19 areas conducted kagura in public buildings. The change in venue from private homes to public buildings represents the change in kagura itself as it moved from traditional to modern. Furthermore, the number of tourists from outside of Takachiho

\footnotetext{
${ }^{2}$ Since the kagura revived in an area, it was practiced in 20 areas in 2011.

${ }^{3}$ This tradition includes Takachiho kagura, although kagura from areas other than Takachiho are often performed in public buildings, in the areas surrounding shrines, in prefabricated structures, or in theaters outside residential areas rather than in private homes.
} 
has increased considerably during recent years ${ }^{4}$.

I attended 11 kagura during the 2009-2010 and 2010-2011 seasons. Information on the 11 areas is presented in Table 1. I counted the number of audience members in and around the kagurayado at the start of each dance. Because the audience members were not uniformly distributed within the kagurayado during performances, it was impossible to ascertain the exact number of attendees. Thus, I approximated the number of audience members, which was sufficient to reflect trends. Figure 1 shows two typical examples of the number of audience members during kagura performed at a private home and a public building, respectively. The audience peaked earlier in the public buildings than in the private homes. In the public buildings, the audience decreased to almost to its nadir by the finale of kagura. In contrast, the number recovered to almost its peak by the finale of performances at private homes. The minimal audiences at midnight and at the finale of kagura performed in public buildings compared with those performed in private homes reflects the loss of the traditional meaning of kagura as a festival event. Indeed, even those performances of kagura that occurred at private homes included many tourists in the audiences. Nowadays, residents cannot realistically ensure the stability of their community through kagura.

Thus far, this paper has introduced three dichotomous categories of people in Takachiho: community members versus outsiders, residents versus tourists, and dancers versus audiences $^{5}$. Dancers are virtually necessarily residents, whereas

Table 1.

Kagurayado, experienced and young dancers by area.

\begin{tabular}{ccccccc}
\hline & \multicolumn{2}{c}{ Kagurayado } & \multicolumn{2}{c}{ Experienced } & \multicolumn{2}{c}{ Young } \\
\cline { 2 - 7 } & 2009-2010 & $2010-2011$ & $\begin{array}{c}\text { Present } \\
\text { age }\end{array}$ & $\begin{array}{c}\text { Start } \\
\text { age }\end{array}$ & $\begin{array}{c}\text { Present } \\
\text { age }\end{array}$ & $\begin{array}{c}\text { Start } \\
\text { age }\end{array}$ \\
\hline A & Private & Private & 58 & 18 & 37 & 33 \\
B & Private & Private & 76 & 17 & 30 & 23 \\
C & Private & Private & 60 & 18 & 34 & 11 \\
D & Private & Private & 57 & 20 & 20 & 8 \\
E & Private & Private & 57 & 17 & 23 & 11 \\
F & Public & Private & 71 & 18 & 27 & 11 \\
G & Public & Public & 61 & 17 & 18 & 3 \\
H & Public & Public & 58 & 20 & 26 & 23 \\
I & Public & Public & 54 & 30 & 32 & 24 \\
J & Public & Public & 56 & 14 & 22 & 19 \\
K & Private & Public & 72 & 30 & 37 & 35 \\
\hline
\end{tabular}

${ }^{4}$ The two most famous magazines for domestic tourists, Rurubu (JTB cooperation) and Mappuru (Shoubun-sha cooperation), cover Takachiho kagura every year. Rurubu initially covered not only Takachiho kagura but also other kaguras performed in Miyazaki prefecture. Since 2002, the magazine has devoted the most space to Takachiho kagura, and since 2007, the magazine has included only Takachiho kagura. Mappuru also initially covered many kaguras in the prefecture. Since 2004, however, it has primarily covered Takachiho kagura, and since 2008, it has covered Takachiho kagura exclusively.

${ }^{5}$ This paper intentionally avoided the use of notions related to hosts and guests (Smith, 1989). Although these ideas are important in the sociology of tourism, they may obscure the topic of this paper. audiences include residents and tourists. Thus, we can classify people into dancers, residents in the audience, and tourists. The issue in this regard is where to locate the boundary between community members and outsiders. Figure 2 presents four hypotheses: 1) Community members are restricted to dancers, whereas all audience members are outsiders. This hypothesis is rejected because kagura is supported by many residents (Fukushima, 2003); 2) All residents are community members, and all tourists are outsiders. This hypothesis sounds naïve now because some residents originated from outside the rural communities; 3) Dancers and some of the residents in the audience are community members, whereas the other residents in the audience and all tourists are outsiders. This hypothesis may be correct because some residents are not motivated to be embedded in the rural communities, as implied in hypothesis 2; 4) Community members include dancers, some residents in the audience, and some tourists. This hypothesis may also be correct if tourism associated with Takachiho kagura welcomed some tourists as community members. If this hypothesis were supported, the creation of communities by residents and tourists may be possible.

\section{Experienced Dancers}

In 2010, I interviewed 11 experienced dancers who served as the leader in their respective areas (Table 1). All were patriarchs. This section discusses the experienced dancers' understandings of kagura. Hereafter, I will refer to each dancer in

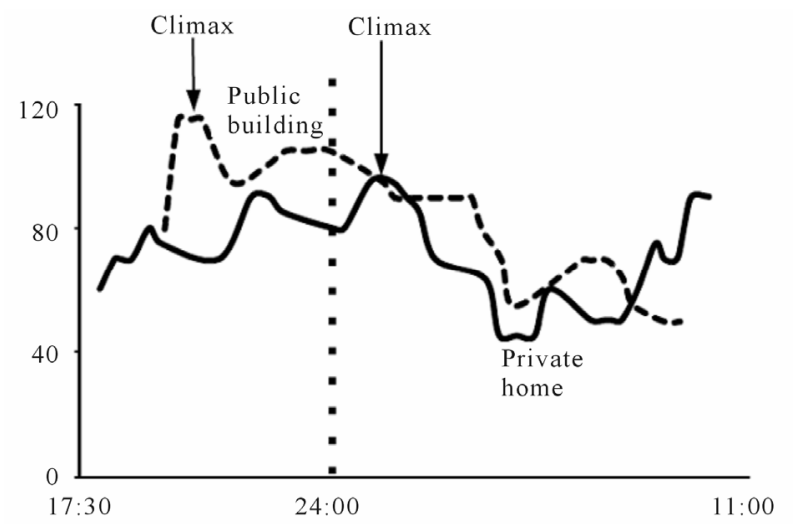

Figure 1.

The numbers of audience members in a private home (solid curve: area A, the 2010-2011 season) and in a public building (dashed curve: area J, the 2009-2010 season). The dotted line indicates 24:00.

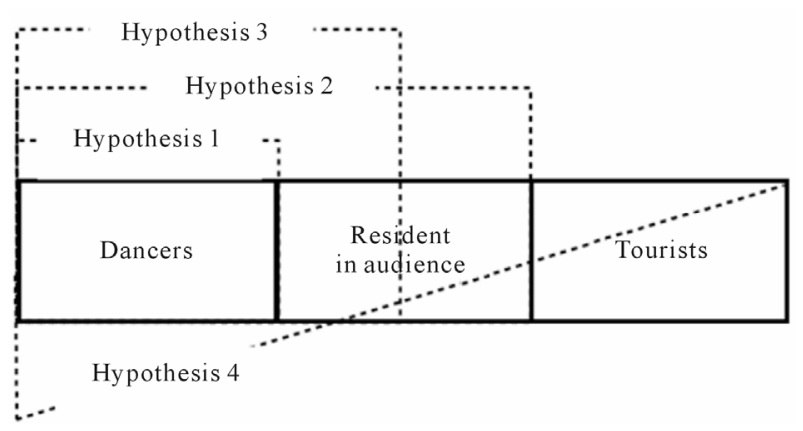

Figure 2.

Four hypotheses about the boundaries of community members. 
terms of the area of his kagura group.

Many experienced dancers reported that kagura was not a show for an audience but rather a prayer to the spirits. In this sense, they were sorry about the change in venue from private homes to public buildings because the relationship between residents and spirits changed accordingly. Dancer $\mathrm{G}$ told me that the owners of kagurayado had assumed important roles, including receiving gifts from the spirits (dancers). Kagura performed in public buildings involved no such owners, and spirits (dancers) had to select audience members to receive gifts as part of the ceremony for the sake of convenience. Many experienced dancers missed the intimate interactions among the residents at old-style kagura performances.

Dancers in areas in which kagura could continue to be performed in private homes took pride in their traditional kagura. Dancer B proudly told me that their kagura was famous because they had defended their traditional styles by performing kagura in private homes each year. He also shared his deeply felt attitudes about local traditions, as represented by kagura. Indeed, Dancer B thought that the traditions had made him a man. Dancer C also told me that they would not stop performing kagura at private homes, and that they would continue to pray for local spirits even if they could not perform kagura due to depopulation and aging.

In contrast, some dancers expressed neutral or even positive impressions of the change in kagurayado. Although they tentatively told me the size of the audience for kagura did not matter, they also eagerly welcomed large audiences. The audience capacity is usually larger at public buildings than at private homes. Indeed, public buildings also have more space for parking, rendering kagura more accessible to tourists who travel long distances by car. Dancer J told me that the influx of tourists contributed to the beautiful dances in their kagura and noted that the dancers in his group worked hard during training. In areas $\mathrm{F}$ and $\mathrm{K}$, residents performed kagura in both private homes and public buildings. Leaders in both areas told me that the atmosphere of kagura performed in private homes did not differ from that performed in public buildings.

Some dancers created unique kagura based on interactions with tourists. In area $\mathrm{D}$, children younger than 18 played central roles in kagura. The leader told me he started kagura that involved primarily children after he assumed his position. He hoped their kagura would become famous among the areas of Takachiho by performing such unique kagura. Some years ago, a woman was accidentally invited into the sacred place of $k a-$ gura in area $\mathrm{H}$, a practice that was strictly forbidden in all other areas of Takachiho. The woman married a man who was also invited to the sacred place. The leader told me that the dancers interpreted the consequence as the will of the spirits. Welcoming women into kagura has now become part of a new local culture in that area.

Dancer A told me they once changed their kagura so that audiences would be more likely to enjoy the performance. They were proud that their kagura attracted large audiences at theaters and prepared new costumes for kagura to impress audiences. After the experience of presenting kagura in shows, they also recognized the value of the traditional kagura and recently returned to a traditional form. They currently use clothes that were worn more than 200 years ago and have found that such traditional kagura also attracted large audiences who sought authentic culture.

\section{Young Dancers}

I asked each experienced dancer to introduce me to a young dancer who was active in his group, and I also interviewed these young dancers (Table 1). All were males.

It has often been assumed that young people leave rural areas to go to cities to pursue jobs, studies, and leisure activities. Thus, I asked the young dancers whether they wanted to leave their rural areas and live in cities. Contrary to my expectations, no respondent reported hoping to live in a city. Some had already left their hometowns and lived in cities, but they became tired of city life and returned.

Dancer G lived together with their parents, and his father was also a dancer in the kagura group. He told me that he had been trying to find jobs in Takachiho since he was a child to enable him to continue kagura and that he had been successful in these efforts. In response to my asking why his desire to continue kagura was so strong, he told me that performing kagura had been fun during his childhood because it allowed him to earn money. At present, he loved kagura as a sophisticated dance and tried hard to perform his kagura with beauty. His father told me that his son remained a novice because kagura was a sacred matter involving the spirits. Nevertheless, he noted that his son's kagura was sophisticated and that he was proud of him. Dancers in all areas and from different generations engaged in many discussions pertinent to this research. Many young dancers told me that they were pleased because kagura had enabled them to develop friendships with local residents from different generations.

Young dancers welcomed tourists from distant areas. Dancer D made friends with a tourist who had taken a photo of his kagura and had won a prize for it. Dancer $\mathrm{H}$ told me that he tried hard to amuse tourists who had come to their kagura from distant areas. All young dancers reported being happy about the possibility of many tourists visiting their area to see kagura because their area would be more likely become the site of a large festival after such exposure. They wanted to continue the tradition of these festivals for their own enjoyment as well as for the enjoyment of residents and tourists. They seemed to believe more strongly than did the experienced dancers in the power of kagura to revitalize their areas.

Dancer A had lived in a city area outside of his home area for more than 10 years before returning and working at the office of tourism in Takachiho. His father was the leader of in the kagura group I interviewed. Based on his experience of living in a city for many years, he appreciated the value of kagura. He told me that residents did not lose their identity because they were naturally motivated to perform kagura. He also noted that such local traditions in rural areas should be preserved not only for the sake of residents but also for the sake of tourists. He hoped that tourists would invest in each area, thereby enabling additional residents to settle in these sites. He viewed this process as a kind of eco-tourism, and he insisted on the importance of having a mediator between residents and tourists to promote such eco-tourism.

Dancer K lived about $130 \mathrm{~km}$ from Takachiho and visited Takachiho every week to perform kagura. Although he was accepted by the leader as a dancer, many other dancers initially distrusted him. However, after much training, he now said he was accepted by the other dancers. He told me he would not move to Takachiho. Instead, he wanted to remain an outsider to advertise the kagura that was performed not only in area $\mathrm{K}$ but 


\section{S. HORIUCHI}

also the kagura that was performed in all areas of Takachiho. Indeed, he wanted to advertise kagura to all people around the world as the Sarutahiko spirit, who mediated between the spirits of heaven and those of earth according to mythology.

\section{Audiences}

I also interviewed audience members during kagura performances. Because we spoke during kagura, each interview was short. In total, I interviewed more than 100 audience members, almost equally divided between males and females. The interviewees ranged from children and elementary school students to seniors who were older than 70 . I did not sample audiences systematically. In the following section, I will present several typical audience members.

Some audience members were residents of Takachiho. For them, kagura was a part of their everyday lives. To attend a kagura festival was a duty of living in their area. Some had lived in Takachiho many years ago. To see kagura was an opportunity for them to visit their homeland. Some were friends or relatives of the dancers. They were invited by dancers to kagura festivals. In response to my question about which elements of kagura appealed to them, they noted elements such as the music, dances, and atmosphere. However, they sometimes needed a longer time to respond, perhaps because kagura was so natural to them, and they were not usually conscious of the elements of kagura that held a particular fascination to them.

Some audience members were tourists seeing kagura for the first time. They came from outside Takachiho, including from Miyazaki (90 km), Fukuoka (130 km), and even Tokyo (850 $\mathrm{km}$ ). I asked them about which elements of kagura appealed to them. Almost all noted that Takachiho was famous for kagura and that they had been interested in kagura or Japanese tradition for a long time, wanting to see kagura at least once. Some had seen kagura in other areas. They presented detailed explanations about the various features of kagura that they found to be fascinating. These elements included not only the music, dances, and stories, but also the local tradition that transmitted kagura for multiple generations as well as the friendly interactions between dancers and audiences.

Some tourists found kagura through a community festival, and a male tourist around 40 had performed kagura in another area. His kagura was about to disappear due to depopulation, aging, and changes in lifestyle, and he sought to identify the factors that enabled kagura to be active in each area and to attract many tourists. One woman around 30 worked in the field of performing arts and was interested in the kagura stage, noting that it was very polished, possibly because of its use by multiple generations. Another woman around 30 drew pictures to depict the intimate relationships between the people and the spirits that appeared in kagura because she was fascinated by the kagura festival.

Some tourists were repeat visitors with strong motivation to continue to see kagura. One male well-known researcher of kagura around 60 told me that he had continually attended kagura festivals to study the evolution of masks. Some dancers of Takachiho kagura wear masks to model the spirits, a practice that informed him about how the masks had been used in ancient times. A female tourist around 40 produced Japanese haiku poems and was interested in Japanese religious traditions, particularly those transmitted in rural areas. To deepen her knowledge of rural religions and her haikus, she attended $\mathrm{ka}$ - gura on a regular basis. A male tourist around 50 continually visited Takachiho to take photos of kagura. He told me about his efforts to capture the fascinating features of kagura in his photos; these efforts were unsuccessful because photos could hardly grasp the intimate atmosphere or the spirits at kagura festivals. These people had intimate friendships with some of the residents. Indeed, some residents welcomed the repeat visitors into their drinking groups during kagura.

Some tourists visited Takachiho frequently not only to see kagura but also to support the community. A woman around 50 had visited an area of Takachiho 7 years earlier for the first time and had continued to visit the area since that time. During the past 4 years, she had guided dozens of tourists to the area every year. By inviting many tourists and encouraging them to invest in the area, she was trying to support the local dancers both financially and emotionally. A man around 40 had once visited Takachiho as a tourist and later moved to Takachiho. This individual was often asked to guide tourists, playing a role as a mediator between residents and tourists. He told me he wanted to educate tourists about the significance of kagura from an objective perspective, a task that was difficult for more established residents because they could hardly be expected to grasp kagura from the standpoint of a tourist. Thus, he tried to provide a bridge between residents and tourists.

\section{Discussion}

Audiences for traditional Takachiho kagura were almost always limited to local residents. Relationships between dancers and audiences were close, which was a feature of classical $\mathrm{ka}$ gura festivals. Interactions between dancers and audience members served to stimulate the community. In contrast, the influx of tourists from outside of Takachiho is a feature of contemporary Takachiho kagura. The cooperative formation of communities by dancers and audiences appears less likely now because contemporary audiences include many tourists. Dancers and audience members can hardly be expected to engage in intimate interactions given the reservations held about one another. Many experienced dancers miss traditional kagura, in which dancers and audience members interacted intimately in private homes.

Nevertheless, this study showed that residents could create a community by cooperating with tourists. Tourists encouraged residents to continue kagura and to reinforce their local identity. Indeed, some experienced dancers approved of the changes in kagurayado because the use of public buildings allowed more tourists to attend performances. Some experienced dancers recreated their traditions in response to tourist demand. Some young dancers tried to stimulate their rural communities by welcoming tourists to their kagura festivals. Some tourists harbored particular motivations to attend kagura festivals and to stimulate rural communities. Thus, residents and tourists can construct kagura in cooperation with each other. Through communication between residents and tourists, kagura is continually reformed; kagura thus becomes a symbol of the community shared by residents and tourists.

It is often assumed that globalization or the influx of outsiders to an area likely leads to the disappearance of local communities and their cultures. However, globalization does not always destroy or ruin local culture; rather, globalization can sometimes promote the revival of local culture through the influx of welcome and helpful outsiders. After freeing them- 


\section{S. HORIUCHI}

selves from unwanted social constraints, many people are eager to be embedded in a community (Beck et al., 1994) in which they find commonalities with other members. People often create such communities with the aid of tradition (Hobsbawm \& Ranger, 1983). Takachiho kagura has a long history that may date to more than 1000 years ago. The content of kagura has changed continually since its inception, and this process of change continues. Although the content of kagura may change, its authenticity must remain intact because residents establish their identity through this tradition. Indeed, contemporary $k a-$ gura brings great meaning to residents.

Tourists often have strong effects on local societies, whereas residents scarcely influence tourists. This asymmetrical relationship between residents and tourists is often a barrier to intimate interactions between the two groups (Smith, 1989). However, in Takachiho, some tourists have been strongly influenced by kagura, even creating new identities by attending their performance. In a critical response to the image that tourists seek only superficial experiences (Boorstin, 1962), MacCannell (1973) defined pilgrimage tourists as those who try to find authentic culture. Pilgrimage tourists are expected to communicate well with residents and may also create communities with residents.

This study suggested that some dancers, immigrants, and tourists adopted important roles as mediators to bridge the gap between residents and tourists. Horiuchi (2008) discussed the role of mediators in decreasing the stress experienced by groups who are separated by distinctions of some sort. In contexts in which people differ significantly from one another, outsiders who have moved between or among groups are often expected to take on the role of mediators (Horiuchi, 2011). Kito (1998) discussed the importance of outsiders in environmental movements. Freed from any connection within the area, outsiders can objectively understand local values and thus act as mediators. Of all the participants in this study, outsiders were most conscious of the maintenance of the community. They therefore tried to act as bridges between residents and tourists.

If mediators bridge differences between peoples, bridging should count as social capital. Granovetter (1973) showed that people benefited from weak ties with people of different groups in the sense that they could use these connections to find good jobs; weak ties may also contribute to the development of whole communities. Putnam (2000) discussed the differences between bonding and bridging social capital. The development of bridging social capital, in which people from different groups interact with one another, enables the stimulation of an entire community. Mediators can revitalize rural communities by bridging the gap between residents and tourists.

Bauman (2001) described two classes of people: people of the lower class, who are restricted by space, and people of the upper class, who are restricted by time. The former are losing local communities, whereas the latter do not sympathize with local communities. However, this study showed that local communities are created by residents who could leave but decided to settle in their home town. Local communities are also created by tourists who seek community with local residents. We cannot simply regard the residents as people of the lower class and tourists as people of the upper class. Indeed, people of the middle class may play central roles in revitalizing local communities, and it is clear that members of the middle class continually try to find their identities. People who are anxious about their identities often create communities that exclude non-members (Young, 1999). The communities of Takachiho kagura, however, do not exclude outsiders. Rather, some outsiders act as mediators that bridge the gap between residents and tourists and thereby activate local communities.

At this point, we can identify where the boundary between community members and outsiders is situated. Of the four hypotheses introduced, hypothesis 4 is likely supported. Mediators are important to making the creation of a cooperative community involving residents and tourists possible. Also necessary is the existence of a local culture that attracts residents and tourists. To enable the development of a comprehensive understanding of the features of local cultures that attract residents and tourists, I suggest that several members of each group be designated as mediators. Additionally, further research is needed to understand the factors that contribute to community creation. It is possible that the local culture of created communities may need to be rooted in the history and nature of the place itself, which would allow all participants to view the existence of the community represented by the local culture as natural (Horiuchi, 2012).

\section{Acknowledgements}

I thank the dancers and audiences of Takachiho kagura for their cooperation. I also thank S. Ogata who introduced me the details of Takachiho kagura. I thank the members of Tokyo Meeting for Mathematical Sociology and the members of Research Group for Common Pool Resources for discussions. This research was financially supported by Grant-in-Aid for Young Scientists (B) "The Conditions for the Residents of Mountains Areas and Urban Areas Cooperate Together” and Meiji University Global COE program "Formation and Development of Mathematical Sciences Based on Modeling and Analysis".

\section{REFERENCES}

Akitsu, M. (1998). Nogyo seikatsu to nettowak: Tsukiai no shiten kara. Tokyo: Ochanomizu Shobou.

Bauman, Z. (2001). Community: Seeking safety in an insecure world. Cambridge: Polity Press.

Beck, U., Giddens, A., \& Lash, S. (1994). Reflexive modernization: Politics, tradition and aesthetics in the modern social order. Stanford, CA: Stanford University Press.

Boorstin, D. J. (1962). The Image: A guide to pseudo-events in America. New York: Harper.

Cohen, E. (1988). Authenticity and commoditization in tourism. Annals of Tourism Research, 15, 371-386. doi:10.1016/01607383(88)90028-X

Cohen, A. P. (1985). The symbolic construction of community. London: Tavistock Publications.

Coleman, J. S. (1988). Social capital in the creation of human capital. American Journal of Sociology, 94, S95-S120. doi:10.1086/228943

Delanty, G. (2003). Community. London: Routledge.

Fukushima, M. (2003). Takachiho yokagura no kenko shinrigakuteki kenkyuu. Tokyo: Kazama Shobou.

Granovetter, M. S. (1973). The strength of weak tie. American Journal of Sociology, 78, 1360-1380. doi:10.1086/225469

Hechter, M. (1987). Principles of group solidarity. Berkeley: University of California Press.

Hobsbawm, E., \& Ranger, T. (Eds.) (1983). The invention of tradition. New York: Cambridge University Press.

Horiuchi, S. (2008). Affiliative segregation of outsiders from a community: Bonding and bridging social capital in Hachimori, Japan. International Journal of Japanese Sociology, 17, 91-100. 


\section{S. HORIUCHI}

doi:10.1111/j.1475-6781.2008.00111.x

Horiuchi, S. (2011). Which negotiators contribute to community formation? Analysis by agent based model. Sociological Theory and Methods, 26, 51-66.

Horiuchi, S. (2012). The boundary between "bad" and "good" outsiders and the construction of unifying elements underpinning rural communities. In J. A. Jaworski (Eds.), Advances in sociology research (Vol. 12), New York: Nova Science Publishers.

Hoshino, H. (2009). Mura no dento geinou ga abunai. Tokyo: Iwata Shoin.

Hosoya, T. (1998). Gendai to nihon no-son shakaigaku. Miyagi: Tohoku University Press.

Kito, S. (1998). The "yosomono (outsider)" concept in the study of environmental movements: Through the case of nature-rights movements in Isahaya and Amami. Kankyo Shakaigaku Kenkyu, 4, 44-59.

Kotegawa, Z. (1976). Takachiho kagura. Miyazaki: Kotegawa Zenjiro Iko Shuppankai.

Lamont, M., \& Molnar, V. (2002). The study of boundaries in the social science. Annual Review of Sociology, 28, 167-195. doi:10.1146/annurev.soc.28.110601.141107

MacCannell, D. (1973). The tourist: A new theory of leisure class. California: University of California Press.

MacIver, R. M. (1917). Community: A sociological study. London: Macmillan.

Moon, O. (1989). From paddy field to ski slope: The revitalization of tradition in Japanese village life. New York: Manchester University Press.

Nash, D. (1996). Anthropology of tourism. New York: Pergamon.

Olson, M. (1965). The logic of collective action: Public goods and the theory of groups. Cambridge: Harvard University Press.

Orikuchi, S. (2003). Kodai kenkyu III. Tokyo: Tyuo-Koron.

Ostrom, E. (1990). Governing the commons: The evolution of institutions for collective action. Cambridge: Cambridge University Press.

Putnam, R. D. (2000). Bowling alone: The collapse and revival of American community. New York: Simon \& Schuster.

Smith, V. L. (Eds.) (1989). Hosts and guests: The anthropology of tourism (2nd ed.). Philadelphia: University of Pennsylvania Press.

Smith, V. L., \& Eadington, W. R. (1992). Tourism alternative: Potentials and problems in the development of tourism. Philadelphia: University of Pennsylvania Press.

Suzuki, E. (1968). Nihon noson shakaigaku genri. Tokyo: Miraisha.

Tönnies, F. (1887). Gemeinschaft und gesellschaft. Leipzig: Fues’s Verlag

Yamaguchi, Y. (2000). Miyazaki no kagura. Miyazaki: Komyakusha.

Yamamoto, S. (Eds.) (2003). Shinrin borantia ron. Tokyo: Nihonringyo chosakai.

Yamashita, S. (2003). Bali and beyond: Explorations in the anthropology of tourism. New York: Berghahn Books.

Young, J. (1998). The exclusive society: Social exclusion, crime and difference in late modernity. London: Sage publications. 